\title{
Expressão gênica do colágeno em ferida cutânea de equinos tratada com plasma rico em plaquetas $^{1}$
}

\author{
Maria V. de Souza ${ }^{2 *}$, José de O. Pinto ${ }^{3}$ Marcela B.M. da Costa ${ }^{4}$, Murilo S. Alves ${ }^{5}$, \\ Micheline O. da Silva ${ }^{6}$, Karina O. Martinho ${ }^{7}$ e Luciano G. Fietto ${ }^{8}$
}

\begin{abstract}
Souza M.V., Pinto J.O., Costa M.B.M., Alves M.S., Silva M.O., Martinho K.O. \& Fietto L.G. 2014. [Collagen gene expression in skin wound of horses treated with plateletrich plasma.] Expressão gênica do colágeno em ferida cutânea de equinos tratada com plasma rico em plaquetas. Pesquisa Veterinária Brasileira 34(3):233-240. Departamento de Veterinária, Universidade Federal de Viçosa, Campus Universitário s/n, Viçosa, MG 36570 000, Brazil. E-mail: msouza@ufv.br

Platelet-rich plasma (PRP) is a product derived from total blood centrifugation, whose use is focused on improving the healing of different tissues, as a result of the growth factors it contains. However, the clinical benefits of this therapy have not been fully established. The objective of this study was to evaluate type I and III collagen gene expression during different phases of the healing process of PRP-treated skin. Eight healthy crossbred geldings, aged 16 and 17 years $(16.37 \pm 0.52)$ were used. Three quadrangular-shaped lesions $\left(6.25 \mathrm{~cm}^{2}\right)$ were surgically induced in the right and left gluteal regions of all the animals. Twelve hours after induction of the lesions, $0.5 \mathrm{~mL}$ of PRP was administered in each of the four edges of the wounds ( $\mathrm{T}=$ treated group) in one of the gluteal regions, randomly chosen. The contralateral region was used as control (NT=non-treated group). The wounds were submitted to daily cleaning with Milli-Q water, and the samples were obtained with a $6 \mathrm{~mm}$ diameter biopsy Punch. Six skin biopsies were obtained, with the first being performed on the day the lesions were induced (T0), and the others 1 (T1), 2 (T2), 7 (T3), and 14 (T4) days, after the wound was induced. The sixth biopsy (T5) was performed after fully healed of the skin. Evaluation of type I and III collagen gene expression was carried out by the qRT-PCR technique. The data were analyzed by the Bonferroni test, Student t-test, paired t-test, and regression analysis $(p<0,05)$. Difference $(p<0.05)$ between groups were observed for both collagen gene expressions from T1 to T4, being higher in the animals of group T. The peak for type I and III collagen gene expressions occurred in T5 for both groups, but the highest expression was different $(\mathrm{p}<0.05)$ from zero time, starting in $\mathrm{T} 3$. In the animals of treated group, collagen expression started to establish at T5, while in the horses of NT group, the values remained increased. Local administration of a single PRP dose in cutaneous wound of the gluteal region of horses results in a higher local gene expression of type I and III collagens. However, this expression does not alter the maximum time of macroscopic healing of the wound.
\end{abstract}

INDEX TERMS: Horses, platelet-rich concentrate, dermatopathy, collagen synthesis, qRT-PCR.

\footnotetext{
${ }^{1}$ Recebido em 19 de novembro de 2013.

Aceito para publicação em 25 de março de 2014.

${ }^{2}$ Departamento de Veterinária, Universidade Federal de Viçosa (UFV), Campus Universitário, Avenida Peter Henry Rolfs s/n, Viçosa, MG 36570000, Brasil. *Autor para correspondência: msouza@ufv.br

${ }^{3}$ Doutorando do Departamento de Veterinária, UFV, Campus Universitário s/n, Viçosa, MG 36570-000. E-mail: jolip2004@yahoo.com.br

${ }^{4}$ Graduanda do Departamento de Veterinária, UFV, Viçosa, MG 36570 000. Bolsista PIBIC-CNPq. E-mail: marcela.martins@ufv.br
}

\footnotetext{
${ }^{5}$ Doutorando do Departamento de Bioquímica e Biologia Molecular, UFV, Campus Universitário, Avenida Peter Henry Rolfs s/n, Viçosa, MG 36570-000, Brasil. E-mail: murilobqi@yahoo.com.br

${ }^{6}$ Mestranda do Departamento de Veterinária, UFV, Campus Universitário s/n, Viçosa, MG 36570-000. E-mail: micheline.silva@ufv.br

${ }^{7}$ Doutoranda do Departamento de Nutrição e Saúde, UFV, Campus Universitário s/n, Viçosa, MG 36570-000. E-mail: kkmartinho@yahoo.com.br

${ }^{8}$ Departamento de Bioquímica e Biologia Molecular, UFV, Campus Universitário s/n, Viçosa, MG 36570-000. E-mail: lgfietto@ufv.br
} 
RESUMO.- 0 plasma rico em plaquetas (PRP) é um produto derivado da centrifugação do sangue total, cuja utilização concentra-se em melhorar a reparação de diferentes tecidos, tendo em vista os fatores de crescimento nele contido. Entretanto, os benefícios da terapia no contexto clínico ainda não estão totalmente esclarecidos. Objetivou-se avaliar a expressão dos genes dos colágenos tipos I e III durante diferentes fases do processo de cicatrização da pele tratada com PRP. Foram utilizados oito equinos machos castrados, mestiços, hígidos, com idade entre 16 e $17(16,37 \pm 0,52)$ anos. Três feridas em formato quadrangular $\left(6,25 \mathrm{~cm}^{2}\right)$ foram confeccionadas nas regiões glúteas direita e esquerda de todos os animais. Doze horas após indução das lesões, $0,5 \mathrm{~mL}$ do PRP foi administrado em cada uma das quatro extremidades das feridas ( $\mathrm{T}=$ grupo tratado), de uma das regiões glúteas, escolhida aleatoriamente. A região contralateral foi utilizada como controle (NT=grupo não tratado). As feridas foram submetidas à limpeza diária com água Milli $\mathrm{Q}$ e amostras foram obtidas com biópsias utilizando-se Punch de $6 \mathrm{~mm}$ de diâmetro. Seis biópsias de pele foram obtidas a primeira no dia de indução das lesões (T0), e as demais com 1 (T1) 2 (T2) 7 (T3) e 14 (T4) dias após a realização das feridas. A sexta biópsia (T5) foi realizada após o completo fechamento da pele. A avaliação da expressão dos genes dos colágenos tipos I e III foi realizada pela técnica qRT-PCR e os dados analisados pelo teste de Bonferroni, t de Student, t pareado e análise de regressão $(\mathrm{p}<0,05)$. Diferenças $(\mathrm{p}<0,05)$, entre grupos, foram observadas para a expressão de ambos os colágenos nos T1 a T4, sendo maior nos animais do grupo T. 0 pico de expressão dos colágenos tipos I e III ocorreu no T5 para ambos os grupos, mas a maior expressão foi diferente $(p<0,05)$ do tempo zero a partir do T3. Nos animais do grupo tratado a expressão dos colágenos começou a estabilizar no T5, enquanto que nos equinos do NT os valores permaneceram elevados. A administração local de uma única dose do PRP em ferida cutânea na região glútea de equinos, resulta em maior expressão gênica local dos colágenos tipos I e III. Entretanto, essa expressão não altera o tempo máximo de fechamento macroscópico da ferida.

TERMOS DE INDEXAÇÃO: Cavalos, concentrado rico em plaquetas, dermatopatia, síntese de colágeno, qRT-PCR.

\section{INTRODUÇÃO}

Feridas cutâneas acarretam importante impacto financeiro na indústria equina (Theoret et al. 2013). 0 processo de cicatrização de feridas envolve uma complexa interação entre diferentes tipos celulares, citocinas, e moléculas da matriz extracelular, que atuam no local, e em conjunto com numerosos fatores sistêmicos como as plaquetas, a cascata de coagulação e componentes celulares e humorais do sistema imune (Soo et al. 2002).

A melhor forma de cicatrização de uma ferida cutânea é por primeira intenção (Ruszczak 2003, Theoret et al. 2013) mediante sutura cirúrgica, o que deve ser realizado o mais rápido possível depois de ocorrida a lesão. Esse procedimento é limitado às feridas localizadas em regiões anatômicas que permitam excisão e adaptação das suas bordas (Ruszczak 2003). Feridas amplas e profundas normalmen- te não possibilitam o fechamento primário, devendo ocorrer a cicatrização por segunda intenção, onde participam ativamente dois processos que são independentes, a contração e a reepitelização (Enoch \& Leaper 2007). Por outro lado, a cicatrização por segunda intenção ocorre de forma lenta, sendo susceptível a complicações como infecção e formação de tecido de granulação exuberante. Nesse contexto, a cada dia surgem novas terapias com a finalidade de reduzir o período máximo de cicatrização das feridas cutâneas, e que resulte na formação de um tecido que seja o mais semelhante possível ao sadio.

0 plasma rico em plaquetas (PRP) é um produto derivado da centrifugação do sangue total, rico em uma variedade de fatores de crescimento, que participam ativamente no processo de cicatrização de feridas cutâneas, como o transformante beta (TGF- $\beta$ ) e o derivado das plaquetas (PDGF), já que estão relacionados com a secreção da colagenase e estímulo à síntese do colágeno (Bames et al. 1999, Schwartz et al. 2002, Marsolais \& Frenette 2005), tanto do tipo I como do tipo III, que são os principais componentes estruturais do tecido cicatricial maduro, sendo sintetizado por fibroblastos (Czubryt 2012, Yang et al. 2013). Em condições fisiológicas, o processo de reparação requer a ativação e/ou supressão de muitos genes, de forma que, uma alteração na expressão gênica pode resultar em uma cicatrização anormal da ferida cutânea.

Apesar da importância do PRP como opção terapêutica, não há suficiente evidência que confirme a sua eficácia no tratamento de feridas cutâneas. Existem alguns estudos com PRP na pele de equinos (Carter et al. 2003, De Rossi et al. 2009, Monteiro et al. 2009, Maciel et al. 2012), mas com resultados contraditórios. São poucas as pesquisas avaliando a resposta terapêutica utilizando técnicas com alta especificidade e sensibilidade como a qRT-PCR, e que avaliaram o perfil de expressão gênica do colágeno. Adicionalmente, a maioria dos resultados utilizando técnicas altamente sensíveis foi obtida a partir de estudos realizados com culturas de células, e pesquisas in vivo sobre o monitoramento da síntese do colágeno são limitadas. 0 estudo da expressão de genes específicos in vivo, em diferentes fases da cicatrização da pele tratada com PRP, pode fornecer informações valiosas sobre parte desse complexo processo. Além disso, os resultados obtidos serão utilizados para validar ou não a eficácia do PRP na cicatrização de feridas cutâneas, testando a hipótese de que o PRP possui efeito anabólico sobre a expressão gênica da matriz. Nesse sentido, o objetivo desse estudo foi avaliar a expressão dos genes dos colágenos tipos I e III durante diferentes fases do processo de cicatrização da pele tratada com PRP.

\section{MATERIAL E MÉTODOS}

Essa pesquisa foi aprovada pela Comissão de Ética no Uso Animal (CEUA) da Universidade Federal de Viçosa (UFV) sob o número de protocolo 96/2011. Os procedimentos foram realizados de acordo com as Normas de Conduta para o Uso de Animais no Ensino, Pesquisa e Extensão do Departamento de Veterinária (DVT/UFV), o Código de Ética Profissional do Médico Veterinário, os princípios éticos para pesquisa animal, estabelecidos pelo Colégio Brasileiro de Experimentação Animal e a Legislação Brasileira vigente. 
Foram utilizados oito equinos mestiços hígidos, machos castrados, com idade entre 16 e $17(16,37 \pm 0,52)$ anos. Apenas animais aparentemente sadios e sem afecção dermatológica foram incluídos no estudo. Uma vez selecionados, os equinos foram colocados em baias individuais de $20 \mathrm{~m}^{2}$, quinze dias antes do início do experimento, onde foram alimentados com feno de tifton 85 e capim elefante picado (Pennisetum purpureum), além de ração farelada própria para equinos. Sal mineral e água foram deixados ad libitum. Esse manejo foi mantido durante todo o ensaio. No período de adaptação os animais foram pesados, pulverizados com solução carrapaticida contendo deltametrina, e vermifugados por via oral com moxidectina $(0,2 \mathrm{mg} / \mathrm{kg} /$ oral $)$.

Três lesões de pele em formato quadrangular foram confeccionadas na região glútea direita e esquerda de todos os animais, conforme descrito por Ferreira et al. (2007). Para isso, o local foi submetido a tricotomia e preparado assepticamente com digluconato clorexidine degermante a $2 \%$ e alcoólico a $0,5 \%$. Os animais foram sedados com xilazina a $2 \%(0,8 \mathrm{mg} / \mathrm{kg} / \mathrm{IV})$, e em seguida foi realizado bloqueio anestésico subcutâneo com cloridrato de lidocaína a $2 \%$, sem vasoconstritor, ao redor do local a ser incidido.

Bisturi com lâmina no23, e um molde de plástico em formato quadrangular com $2,5 \mathrm{~cm}$ de lado $\left(6,25 \mathrm{~cm}^{2}\right)$ foram utilizados para a confecção da lesão cutânea (epiderme, derme e tecido subcutâneo). As feridas foram identificadas em A, B e C, craniocaudalmente em ambas as garupas. Amostras de pele foram congeladas a $-80^{\circ} \mathrm{C}$ para posterior avaliação da expressão gênica do colágeno (T0). As feridas foram deixadas para cicatrizarem por segunda intenção, e monitoradas até completo fechamento (ferida C). Todos os animais receberam soro antitetânico no dia de confecção da lesão de pele. A dor foi reduzida utilizando dose única de tartarato de butorfanol $(0,08 \mathrm{mg} / \mathrm{kg} / \mathrm{IV})$. Não foram utilizadas fármacos anti-inflamatórios e antibióticos.

A obtenção do PRP foi baseada no protocolo descrito por Argüelles et al. (2006). Após antissepsia local com álcool-iodado, $144 \mathrm{~mL}$ de sangue foram obtidos com agulhas vacutainer por venipunção jugular, e acondicionados em 36 tubos com capacidade para 4,5mL, contendo citrato de sódio a 3,2\%. Também foram obtidas amostras de sangue com EDTA para quantificação das plaquetas e leucócitos totais.

As amostras de sangue para a obtenção do PRP foram homogeneizadas e centrifugadas a $120 \mathrm{xg}$ por $10 \mathrm{~min}$. Após centrifugação, foi descartado de cada tubo, $50 \%$ do plasma sanguíneo presente na superfície e o restante foi transferido para quatro tubos de polipropileno sem anticoagulante com capacidade para $10 \mathrm{~mL}$, sendo o botão leucocitário e as hemácias sedimentadas descartados. Em seguida, o plasma foi novamente centrifugado a $240 \mathrm{xg}$ por $10 \mathrm{~min}$. Após essa segunda centrifugação o plasma foi dividido em duas frações: o sobrenadante (plasma pobre em plaquetas) e a fração remanescente denominada plasma rico em plaquetas. Um volume de $75 \%$ do plasma obtido, presente na superfície de cada tubo foi descartado e o PRP contendo o botão de plaquetas, reservado.

A concentração das plaquetas e dos leucócitos foi determinada manualmente (método Rees \& Ecker 1923) no PRP e no sangue obtido com EDTA. A quantificação foi realizada em câmara de Neubauer utilizando líquido de Türk para contagem dos leucócitos e de Brecher para contagem das plaquetas (Thrall 2007).

Todos os animais foram submetidos a tratamento local com PRP $12 \mathrm{~h}$ após realização das lesões. Após tricotomia e sedação com xilazina $(0,8 \mathrm{mg} / \mathrm{kg} / \mathrm{IV})$, uma das regiões glúteas, escolhidas ao acaso, foi assepticamente preparada para a administração do PRP (grupo T). As feridas da região glútea contralateral (grupo NT) não receberam qualquer infiltração, mas apenas limpeza local com água Milli-Q sendo o mesmo realizado nas feridas tratadas.

O PRP foi preparado imediatamente antes da sua aplicação, que foi realizada utilizando-se agulha de 24G. Cada extremidade das três feridas recebeu $0,5 \mathrm{~mL}$ do componente rico em plaquetas, totalizando $2 \mathrm{~mL}$ por lesão e $6 \mathrm{~mL}$ por região glútea (esquerda ou direita). Após tratamento, os animais foram mantidos em baias, sendo soltos por um período diário de $2 \mathrm{~h}$, e monitorados durante todo o experimento.

Amostras de pele, em toda a sua superfície lesionada, foram obtidas para a expressão gênica do colágeno, conforme metodologia descrita por Monteiro et al. (2009) e Deschene et al. (2011). A obtenção foi realizada com Punch de $6 \mathrm{~mm}$ de diâmetro um (T1) e dois (T2) dias após realização da lesão, assim como sete (T3) e 14 (T4) dias do procedimento cirúrgico. Adicionalmente, uma nova coleta foi realizada ao término do fechamento da ferida "C" (T5).

Para as biópsias, os animais foram submetidos a protocolo anestésico similar ao utilizado para a confecção das lesões, descrito anteriormente. A exceção da última coleta que foi realizada no centro da área cicatrizada (que ainda se mostrava despigmentada), as amostras foram retiradas da periferia das lesões. Foram obtidas duas amostras de pele em cada tempo. Após obtenção dos fragmentos cutâneos, o excesso de sangue foi retirado de forma asséptica com $\mathrm{NaCl}$ a $0,9 \%$. Ato contínuo, foram colocados em criotubos e imersos em nitrogênio líquido a $-196^{\circ} \mathrm{C}$ por alguns segundos e estocados em freezer a $-80^{\circ} \mathrm{C}$. Próximo a realização das análises, os fragmentos foram liofilizados e pesados em balança de precisão. As feridas não tratadas foram submetidas ao mesmo protocolo de avaliação.

Para a determinação do modelo da expressão gênica dos colágenos tipos I e III, as amostras liofilizadas foram descongeladas em temperatura ambiente, e $10 \mathrm{mg}$ foram utilizadas para extração do RNA total usando o reagente Trizol (Life Technologies, Itapevi, São Paulo, Brasil).

Para a síntese dos cDNAs, $4 \mu \mathrm{g}$ de RNA total foram tratados com DNAse (RQ1 DNAse - $1 \mu \mathrm{L} / 2 \mu \mathrm{g}$ de RNA) (Invitrogen, Life Technologies) e utilizados para a síntese de cDNA com a enzima transcriptase reversa MMLV (Invitrogen, Life Technologies).

Após a obtenção dos cDNAs, quantidades equivalentes foram reunidas em quatro amostras contendo cada uma cDNAs provenientes de duas repetições biológicas, totalizando quatro amostras representativas dos oito animais incluídos no experimento.

As análises de PCR quantitativo em tempo real (qRT-PCR) foram realizadas utilizando o aparelho ABI Prism 7500 Sequence Detection System (Applied Biosystems, Life Technologies) de acordo com as recomendações descritas no manual da Applied Biosyste$m s$. As reações foram realizadas em placas ópticas de 96 poços. Cada reação continha um volume final de $10 \mu \mathrm{L}$, sendo $5 \mu \mathrm{L}$ de GoTaq qRT-PCR Master Mix (Promega, Lab-Research do Brasil, São Paulo, Brasil), $4 \mu \mathrm{L}$ dos oligonucleotídeos correspondentes na concentração de $2,5 \mu \mathrm{M}$ e $1 \mu \mathrm{L}$ do cDNA. As condições de amplificação foram: $95^{\circ} \mathrm{C}$ por $10 \mathrm{~min}$ e 40 ciclos de $94^{\circ} \mathrm{C}$ por $15 \mathrm{~s}$, e a $60^{\circ} \mathrm{C}$ por 1 min. Após 40 ciclos de amplificação, todas as amostras foram submetidas à desnaturação gradual para elaboração da curva de dissociação (melting) para atestar a especificidade das amplificações.

A quantificação da expressão dos genes alvo para o colágeno do tipo I - COL1A2 (AB070840.1) e o colágeno do tipo III - COL3A1 (XM_001917620.2) foram baseadas nos valores de Ct (Clycle threshold). Inicialmente foi realizado um ensaio para a determinação da eficiência da reação para cada gene. Para tanto foram realizadas diluições seriadas de $10^{\circ}, 10^{-1}, 10^{-2}$ e $10^{-3}$ do cDNA extraído da última coleta, ou seja, quando ocorreu o fechamento da ferida. As diluições foram utilizadas em reações de qRT-PCR como descrito anteriormente. Para o cálculo da eficiência foi utilizado o coeficiente de correlação obtido pela regressão linear dos valores de Ct das diluições seriadas. Todos os primers utilizados apresentaram eficiência próxima a 100\%.

Para a quantificação relativa foi utilizado o método comparativo de $2^{-\Delta \Delta \mathrm{Ct}}$. Como controle endógeno para normalização dos 
dados foi utilizado a expressão do gene que codifica a enzima gliceraldeído-3-fosfato-desidrogenase (GAPDH-AF157626.1). Os oligonucleotídeos específicos utilizados nos experimento foram: GAPDH-equusF1: GGC AAG TTC CAT GGC ACA GT; GAPDH-equus R1: CAC AAC ATA TTC AGC ACC AGC AT; COL1A2-equus F2: TAT ACT GTG ATT TCT CTA CTG GCG; COL1A2-equus R2: TTG ACC TTG GAG TTT CTG TAC C; COL3A1-equus F1: CTA TGG CAA TCC TGA CCT TCC; COL3A1-equus R1: GCT TGA TCC ATG TAC GCA ATG.

Os dados foram analisados através do software Stata, versão 9.1 Stata Corp., College Station, USA. A análise descritiva das variáveis foi apresentada por meio da média/mediana e desvios padrão. Para avaliação da normalidade da distribuição das variáveis foi utilizado o teste de Shapiro-wilk. As variáveis que não apresentaram distribuição normal foram transformadas em log. 0 teste t de Student para amostras independentes foi utilizado para comparar os grupos tratado e não tratado em cada tempo (T1, T2, T3, T4 e T5) para cada tipo de colágeno, assim como para comparar os valores médios de contagem de plaquetas e de leucócitos no sangue e PRP, e a média do tempo de cicatrização da ferida nos grupos. Para a comparação dos diferentes tempos em ambos os grupos foi utilizado análise de variância (ANOVA) de medidas repetidas. A comparação entre os valores médios de expressão de cada tipo de colágeno em cada grupo foi realizada pelo teste de Bonferroni. Análise de regressão foi realizada para verificar a associação dos tipos de colágeno com o decorrer do tempo $(0,1,2,7$, 14 e 37 dias). A comparação entre os tipos de colágenos em cada tempo no mesmo grupo foi realizada através do teste t pareado. 0 nível de significância adotado foi de $5 \%$.

\section{RESULTADOS E DISCUSSÃO}

O período de tempo para fechamento de uma ferida depende de vários fatores, dentre eles a extensão e localização anatômica da lesão, e a presença de infecção local. 0 processo de cicatrização das feridas nos equinos é muito semelhante ao dos humanos (Theoret et al. 2013), o que se dá por reepitelização da superfície cutânea, com a derme cicatrizando por granulação do estroma, migração de miofibroblastos e contração da ferida (Greenwood 2010). De forma clássica, o processo de cicatrização da pele é dividido em quatro fases bem definidas que se sobrepõem, incluindo hemostasia, inflamação, proliferação e, por último, remodelação (Enoch \& Leaper 2007, Young \& McNaught 2011). Schultz et al. (2011) subdivide a terceira fase em migração e proliferação, e a quarta em contração e remodelação.

No presente estudo o tempo máximo necessário para cicatrização das lesões foi de 47 dias em ambos os grupos de animais, sendo os valores médios de $36,87 \pm 7,45$ dias nas feridas não tratadas com PRP, e de 38,75 $\pm 6,47$ dias nas tratadas, entretanto não houve diferença $(p=0,59)$ entre grupos. Esse tempo médio de cicatrização está próximo ao encontrado em feridas não contaminadas, localizadas na região torácica, que é de aproximadamente quatro semanas (Schwartz et al. 2007), assim como de feridas realizadas da mesma forma e na mesma região que a descrita no presente estudo (38,5 $\pm 3,9$ dias; Ferreira et al. 2007). Os resultados obtidos se assemelham aos descritos por Monteiro et al. (2009), que também observaram que o período máximo de fechamento de feridas tratadas com PRP foi maior do que nas não tratadas, o que sugere que a terapia não tem efeito positivo no tempo máximo de cicatrização macroscópica da lesão de pele.
No sangue total e PRP os valores de plaquetas variaram de 100.000 a 150.000 plaquetas $/ \mu \mathrm{L}$, e de 320.000 a 390.000 plaquetas $/ \mu \mathrm{L}$, respectivamente. Já os valores de leucócitos variaram respectivamente de 5.600 a 10.900 células/ $\mu \mathrm{L}$ e de 50 a 900 células/ $\mu \mathrm{L}$ no sangue total e PRP. 0 valor médio da contagem de plaquetas encontradas no sangue foi menor $(\mathrm{p}=0,000)$ do que no PRP. 0 oposto $(\mathrm{p}=0,000)$ ocorreu com o valor médio de contagem dos leucócitos.

A concentração de plaquetas no PRP foi considerada como adequada, já que foi acima da referida como apropriada por Anitua et al. (2004), e semelhante à obtida em pesquisas realizadas em equinos hígidos mestiços (Maia et al. 2009, Vendruscolo et al. 2012, Zandim et al. 2013). Adicionalmente, estudo in vitro realizado por Graziani et al. (2006) demonstrou que preparações de PRP exercem um efeito dose-específico na proliferação de fibroblastos e osteoblastos. Efeitos ótimos foram observados quando a contagem plaquetária foi 2,5x mais alta do que a presente no sangue total. Por outro lado, quantidades mais elevadas $(5,5 x)$ resultaram em efeitos indesejáveis, como a redução da proliferação fibroblástica, e da função dos osteoblastos. Na opinião dos autores, diferentes concentrações de plaquetas no PRP também podem ocasionar resultados distintos quando estudos in vivo são realizados. Aumento em quantidade moderada da concentração de plaquetas no PRP com relação à contagem no sangue total pode possibilitar um ambiente mais adequado para a cicatrização de feridas devido a um melhor equilíbrio entre proliferação e diferenciação celular. Nesse sentido, como a quantidade de plaquetas no PRP preparado foi em média de 2,8x a presente no sangue total, acredita-se que essa quantidade deveria ter sido suficiente para que a terapia resultasse em efeito positivo na cicatrização da ferida, no que se refere a um fechamento mais rápido. Entretanto, o fechamento macroscópico da lesão não necessariamente reflete a qualidade do tecido cicatricial. Dados preliminares obtidos em pesquisa em andamento têm revelado que fragmentos obtidos na fase final do processo de cicatrização de feridas tratadas com PRP, apresentam-se microscopicamente com melhor organização dos feixes de fibras colágenas em comparação com as lesões não tratadas. Adicionalmente, avaliação descritiva sobre a organização e densidade das fibras de colágeno realizada por Maciel et al. (2012), mediante microscopia eletrônica de varredura, revelou que feridas de equinos tratadas com uma ou duas aplicações tópicas de PRP em gel apresentaram melhor característica ultraestrutural do que as do grupo controle (tratadas com solução salina) na biópsia realizada 25 dias após tratamento. Por outro lado, na avaliação realizada aos 40 dias, as feridas que receberam particularmente duas aplicações do componente rico em plaquetas demonstraram maior densidade tecidual da matriz extracelular, o que de acordo com os autores é indicativo de fibrose. Apesar desse achado, clinicamente a reparação da ferida ocorreu com pouco tecido cicatricial.

Considerando os resultados obtidos no estudo de Maciel et al. (2012), pode-se inferir que uma única aplicação do PRP, conforme ocorreu no presente estudo é uma prática adequada, já que reduz a possibilidade de se aplicar e estimular no local grandes quantidades de fatores 
de crescimento que são conhecidamente associados a cicatriz hipertrófica. Adicionalmente, a concentração média de plaquetas utilizadas por esses autores que foi de $723.000 \pm 50.000$ plaquetas $/ \mu \mathrm{L}$, ou seja, de três a cinco vezes a quantidade presente no sangue total, pode ter atuado estimulado a maior densidade tecidual observada. É importante ressaltar que, apesar de vários pesquisadores considerarem que elevada concentração de plaquetas seja fundamental para a eficácia da terapia, conforme previamente mencionado, pesquisa in vitro sinalizou que quantidades mais baixas como, por exemplo, $2,5 \mathrm{x}$ a presente no sangue total, pode resultar em melhores resultados. Essa afirmativa é reforçada com estudo in vitro realizado por Boswell et al. (2014), onde cultura de tendão de equinos que recebeu PRP contendo diferentes proporções de leucócitos e plaquetas, revelou que o grupo que recebeu maior quantidade de plaquetas apresentou redução na expressão do colágeno tipo I. Por outro lado, o tendão tratado com quantidades mais baixas de leucócitos apresentou menor sinalização catabólica. Na opinião dos autores, os resultados sugerem que o menor efeito catabólico ocasionado pela baixa concentração de células brancas seja, provavelmente, mais importante do que a alta quantidade de plaquetas, cuja finalidade é maximizar o feito anabólico nos tecidos.

A quantidade de leucócitos (50-900 células/ $\mu \mathrm{L}$ ) presente no PRP também foi considerada como adequada, pois foi mais baixa do que a obtida por Vendruscolo et al. (2012) $(2.460 \pm 763$ células $/ \mu \mathrm{L})$, quando utilizaram força de centrifugação relativa $(g)$ e tempo igual ao usado no presente estudo. É indiscutível o efeito positivo dos leucócitos na inflamação, imunidade e sinalização celular (Boswell et al. 2012), assim como na liberação de fatores de crescimento. Por outro lado, aos leucócitos também são atribuídos efeitos indesejáveis, já que ao atuar como sinalizadores de células pró-inflamatórias podem provocar catabolismo tecidual (Jacobsen et al. 2008). Adicionalmente, há relato de que a aplicação de concentrado de plaquetas com leucócitos, para tratamento de paciente com tendinopatia pode aumentar a dor local (Mishra \& Pavelko 2006). Portanto, tanto efeitos positivos como negativos são associados à presença dessas células no PRP. A utilização de um PRP com pequena quantidade de leucócitos, conforme ocorreu no presente estudo, é considerada adequada quando se pretende promover uma ação mais anabólica do que catabólica (Wasterlain et al. 2012), já que as feridas não estavam contaminadas.

A matriz extracelular é uma complexa rede de ligações cruzadas de proteínas e outras macromoléculas, das quais o colágeno é o principal componente estrutural, sendo fundamental para a resistência e integridade de todos os tecidos, possuindo função vital na cicatrização das feridas (Enoch \& Leaper 2007). Considera-se que a síntese de colágeno inicia-se pelo menos a partir do terceiro dia após uma lesão cutânea. Os valores médios e desvios padrão da expressão dos genes dos colágenos tipos I e III na pele tratada e não tratada com PRP são apresentados na Fig.1. A exceção do tempo referente à avaliação final (T5), houve diferença $(p<0,05)$ entre grupos tanto para o colágeno tipo I como para o colágeno tipo III, sendo os valores médios mais elevados nos grupos tratados. Esses resultados demonstram a eficácia do PRP em induzir a expressão dos colágenos durante a fase inflamatória e proliferativa do processo de cicatrização cutânea. Sabe-se que as feridas adquirem aproximadamente $20 \%$ da sua resistência mecânica à tração ao final das três primeiras semanas do início do processo de cicatrização, que é durante o período em que os colágenos fibrilares se acumulam de forma relativamente rápida. Depois desse período a melhora na resistência se torna lenta, particularmente devido ao início da remodelação dos colágenos, que começam a formar grandes feixes de fibras, assim como pelo aumento no número de ligações cruzadas intermoleculares (Bailey et al. 1975), que começam a ocorrer durante a fase de remodelação.

Tanto nas feridas tratadas como não tratadas, a expressão do gene do colágeno tipo I foi mais elevada $(\mathrm{p}<0,05)$ com relação ao tempo zero, a partir da primeira semana (T3), com valores máximos no tempo final $(\mathrm{p}=0,000)$. Lefebvre-Lavoie et al. (2005) utilizaram supressão subtrativa
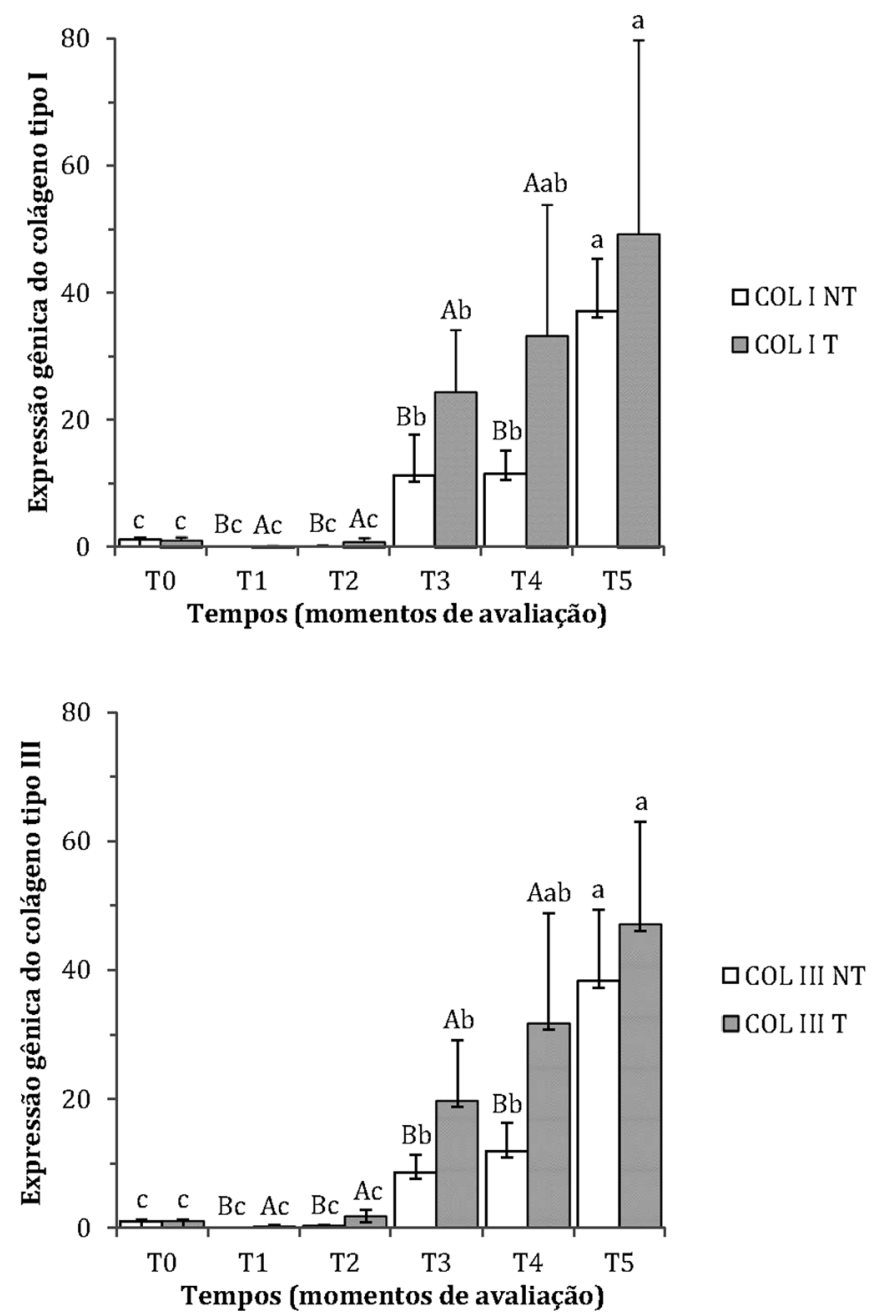

Fig.1. Médias e desvios padrão para a expressão dos genes colágenos tipos I (COL I) e tipo III (COL III), em diferentes tempos do processo de cicatrização, tanto no grupo não tratado (NT) como no grupo tratado (T) com PRP. Médias seguidas por letras maiúsculas e minúsculas diferentes diferem entre si nos grupos e nos tempos pelos testes t de Student e de Bonferroni, respectivamente. 
por hibridização e RT-PCR semi-quantitativa para identificar a expressão gênica do colágeno tipo I tanto na pele sadia como na margem de feridas cutâneas induzidas no hemitorax de equinos. A avaliação foi efetuada após uma semana de realização da lesão, com aumento significativo da expressão do colágeno tipo I nas amostras obtidas a partir das feridas, em comparação com a pele íntegra, em ambas as técnicas utilizadas. Deste modo, tanto em condições fisiológicas, como em feridas tratadas com PRP, existe aumento da expressão do colágeno tipo I já após uma semana que, de acordo com Schultz et al. (2005), corresponde 80 a 85\% da matriz extracelular cutânea.

Da mesma forma que ocorreu com o colágeno tipo I, a expressão do gene do colágeno tipo III foi significativa $(p<0,05)$ a partir da primeira semana de indução das lesões nos animais de ambos os grupos. Esse colágeno corresponde de 8 a $11 \%$ da matriz extracelular cutânea (Schultz et al. 2005), devendo ser produzido em maior quantidade durante a fase final da formação da matriz extracelular. $\mathrm{Na}$ sequência deve ser gradualmente degradado e substituído pelo colágeno tipo I, que é fundamental para aumentar a força do tecido em cicatrização (Mutsaers et al. 1997, Liu et al. 2005, Czubryt 2012), que é reforçada pelas ligações cruzadas dos colágenos (Czubryt 2012).

De acordo com Schwartz et al. (2002) a elevação do colágeno tipo I é progressiva, permanecendo por pelo menos quatro semanas, que foi o período máximo de tempo em que os autores avaliaram esse colágeno utilizando a técnica histoquímica do Picrosirius Red, em feridas de equinos localizadas no tórax e região distal dos membros torácicos, cicatrizadas por segunda intenção. Na realidade, Mignatti et al. (1996) mencionam que a elevada taxa de síntese do colágeno dentro da ferida pode demorar de 6 a 12 meses para retornar aos níveis fisiológicos, o que significa que independentemente se a ferida cutânea é tratada ou não com PRP, a quantidade de colágeno tipo I ainda pode estar elevada no momento do fechamento da lesão.

A análise de regressão revelou que, com o decorrer dos dias, há um aumento de 0,99x e 1,04x na expressão gênica dos colágenos tipos I ( $\left.\mathrm{IC}_{95 \%} ; 0,88-1,1\right)$ e III $\left(\mathrm{IC}_{95 \%} ; 0,91-1,15\right)$ respectivamente, no grupo não tratado. No grupo tratado esse aumento é de respectivamente $1,34 \mathrm{x}\left(\mathrm{IC}_{95 \%} ; 0,96-1,73\right)$ e 1,29x ( IC $\left._{95 \%} ; 1,01-1,56\right)$ (Fig.2). A análise revela que no grupo que recebeu o PRP há uma estabilização da expressão dos colágenos tipos I e III com aproximadamente 31 e 32 dias, respectivamente. De acordo com Czubryt (2012), durante as fases de proliferação e remodelação da cicatrização, a síntese da matriz extracelular inicialmente supera a degradação. No entanto, eventualmente um estado estacionário ocorre entre esses processos, o que coincide com a maturação da cicatriz. Por outro lado a cicatrização excessiva ocorre quando a síntese da matriz permanece elevada por mais tempo que o considerado como normal o que resulta em excesso na produção de colágenos e de outros componentes. Portanto, embora os colágenos sejam essenciais para a integridade estrutural e resistência mecânica dos tecidos, o seu acúmulo anormal pode ocasionar fibrose (Lefebvre-Lavoie et al. 2005, Young \& McNaught 2011). A maior expressão dos genes desses colágenos no grupo
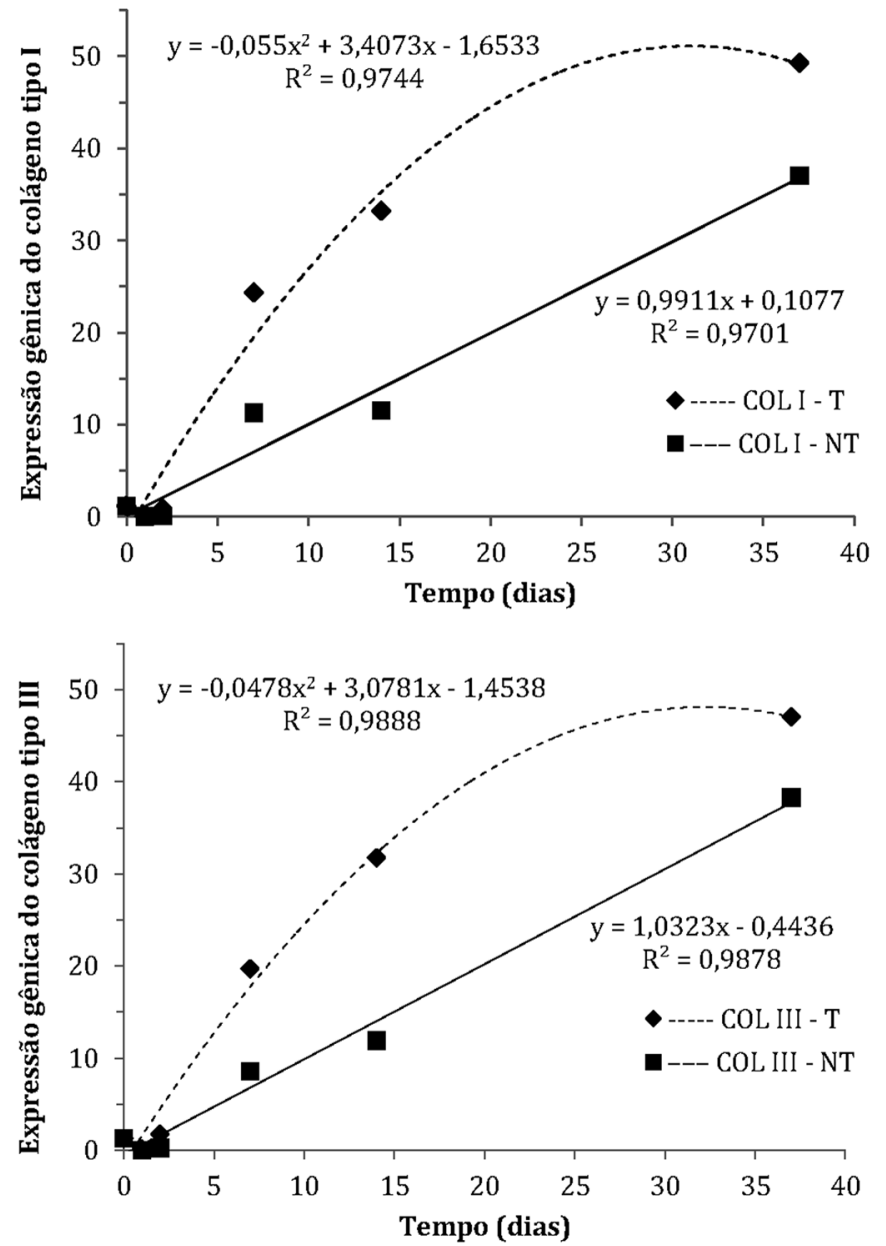

Fig.2. Estimativa da expressão gênica dos colágenos tipos I (COL I) e III (COL III) nos grupos não tratado (NT) e tratado (T), em função do tempo.

tratado pode estar relacionada à presença dos fatores de crescimentos TGF- $\beta$ e PDGF, que são alguns dos considerados como mais importantes no PRP, e que estão associados à produção dos colágenos (Schwartz et al. 2002). Nesse contexto, a tendência de estabilização na expressão dos colágenos no grupo tratado é um aspecto positivo do PRP. É importante ressaltar que esses fatores de crescimentos são encontrados em condições naturais no processo de cicatrização, sendo possivelmente responsáveis pela importante expressão dos colágenos no grupo controle.

A comparação da expressão dos colágenos (I ou III) por grupo revelou que tanto no tratado como no controle, o tipo III foi mais expresso $(p<0,05)$ em relação ao tipo I $48 \mathrm{~h}$ após indução da lesão. Nos demais tempos a expressão não diferenciou. Essa comparação foi possível porque os oligos utilizados para o gene COLIII (COL3 1) apresentaram eficiência de reação $\left(R^{2}=0,9912\right)$ similar aos oligos utilizados para o gene COLI (COL1 2; $\left.\mathrm{R}^{2}=0,9635\right)$. Esse resultado era esperado, pois no estágio inicial do processo de cicatrização ocorre excessiva deposição do colágeno do tipo III, e posteriormente predomina o do tipo I.

A permanência elevada, particularmente do colágeno tipo III na avaliação final, sugere que a ferida ainda se 
encontrava na fase caracterizada por Schultz et al. (2011) como de contração e remodelação, apesar de se mostrarem macroscopicamente cicatrizadas. Essa fase é caracterizada pela diminuição no número de fibroblastos e equilíbrio entre a produção e lise do colágeno. A produção do colágeno deve se manter elevada, mas com predomínio das fibras colágenas funcionalmente orientadas sobre as não funcionais e sem que ocorra aumento no tamanho da cicatriz (Theoret 2008). Por outro lado, de acordo com Schultz et al. (2005), 40 dias após lesão ainda não existe organização suficiente das fibras colágenas. Nesse contexto, a macroscopia não necessariamente corresponde à microscopia nem a expressão de genes de colágenos, pois a natureza dos componentes da matriz da ferida altera ao longo do tempo. Na realidade, durante um período de vários meses ocorrem mudanças na organização do colágeno no tecido em processo de reparação, o que irá aumentar lentamente à resistência do tecido à tração, e que chegará a aproximadamente $80 \%$ da correspondente ao tecido normal (Schultz et al. 2005, Enoch \& Leaper 2007, Young \& McNaught 2011).

Yamauchi \& Mechanic (1988) definem esse estágio do processo de cicatrização após fechamento clínico como intermediário. De acordo com estes autores, embora a ferida se mostre aparentemente cicatrizada, existem alterações químicas e estruturais ainda em andamento. Nessa etapa, as fibrilas de colágeno se mostram agrupadas e estabilizadas pela formação de ligações cruzadas inter e intra-moleculares. Portanto, essa elevada expressão do gene do colágeno ainda nessa etapa intermediária pode ser devido ao fato de que a síntese do colágeno ainda exceda a sua degradação extracelular, de modo que continua aumentando durante a fase de formação da cicatriz (Mutsaers et al. 1997). Mais especificamente, Young \& McNaught (2011) mencionam até dois anos para a maturação do tecido cicatricial, de forma que uma ferida possa adquirir um epitélio o mais próximo possível ao sadio. Nessa fase deve haver equilíbrio entre a síntese e a degradação do colágeno por colagenases oriundas dos fibroblastos, neutrófilos e macrófagos, que quebram a molécula em pequenos fragmentos, que por sua vez se desnaturam e são digeridos por outras proteases. Conforme mencionado anteriormente, nos resultados apresentados nota-se que existe uma tendência a estabilizar a expressão dos colágenos no grupo tratado com PRP, o que é adequado. Para comprovação ou não desse achado será necessária, em pesquisa futura, avaliar a expressão gênica do colágeno em momentos (tempos) posteriores à cicatrização clínica.

A comparação dos resultados obtidos na presente pesquisa com outras relizadas em pele de equino é praticamente impossível, pois são raros os estudos que avaliaram a expressão gênica dos colágenos na pele tratada com PRP utilizando a técnica de qRT-PCR. A comparação com estudos que utilizaram outras metodologias para avaliar o comportamento dos colágenos durante o processo de cicatrização também é difícil, pois os estudos controlados e in vivo são escassos e, em geral, objetivam avaliar de forma muito pontual um tempo específico nas diferentes fases do processo de cicatrização cutânea. Adicionalmente, a maioria dos experimentos foi realizada com culturas de células de tendão ou ligamento. Até a presente data, apenas Monteiro et al. (2009) estudaram a expressão gênica dos colágenos tipos I e III por PCR em feridas de equinos tratadas com PRP, entretanto essa avaliação ocorreu apenas após completa cicatrização das lesões. Os autores compararam a proporção média para a expressão do mRNA para o colágeno tipo I em relação ao III, mas não encontraram diferença $(p>0,05)$ entre grupos tratados e não tratados nos valores médios, que foram de 0,502 $\pm 0,155$ e 0,542 $\pm 0,118$, respectivamente. Carvalho et al. (2013) avaliaram a expressão gênica dos colágenos tipos I e III em tendinopatia tratada com células tronco mesenquimais associada a concentrado de plaquetas. Os autores também não encontraram diferenças entre os grupos tratado e controle (que recebeu tampão fosfato salino) na avaliação realizada 16 semanas após o tratamento, ou seja, na fase de remodelação do processo de reparação tendínea.

Apesar dos resultados obtidos não poderem ser comparados com os de outros estudos, os dados apresentados são inéditos e valiosos para a medicina veterinária. Avaliar alterações em componentes da matriz extracelular é uma forma adequada de monitorar a reparação de tecidos. 0 colágeno, por ser o componente mais abundante do tecido conjuntivo, é fundamental durante a restauração da funcionalidade da pele, e reflete a qualidade da matriz. 0 presente estudo demonstrou a importância do PRP na expressão de colágenos em diferentes fases do processo de cicatrização cutânea em equinos, o que confirma o seu efeito anabólico. 0 ensaio experimental executado em diferentes momentos possibilitou acompanhar a dinâmica do processo cicatricial. A técnica utilizada, a qRT-PCR, é altamente sensível, confiável e facilmente executada, sendo de escolha para pesquisa sobre a expressão gênica em diferentes componentes biológicos. Por outro lado, ainda que os raros estudos possuam dados valiosos sobre densidade, quantificação e/ou expressão gênica dos colágenos na pele de equinos, o perfil dessa expressão na ferida tratada com PRP ainda deve ser mais bem caracterizado. Obtenção de amostras de pele para avaliação de componentes da matriz extracelular, a partir de diferentes períodos após cicatrização macroscópica da lesão, poderá fornecer informações inéditas, e comprovar ou não uma tendência já sinalizada no presente estudo, que é a estabilização mais precoce dos colágenos em feridas tratadas com uma única aplicação do componente rico em plaquetas.

\section{CONCLUSÃO}

A administração local de PRP $12 \mathrm{~h}$ após indução cirúrgica de lesão cutânea na região glútea de equinos resulta em importante aumento da expressão gênica dos colágenos tipos I e III. Entretanto, essa maior expressão não resulta em fechamento mais rápido da ferida cirúrgica.

Agradecimentos.- Os autores agradecem à FAPEMIG, à CAPES e ao CNPq pelo suporte financeiro.

\section{REFERÊNCIAS}

Anitua E., Andia I., Ardanza B., Nurden P. \& Nurden A.T. 2004. Autologous platelet source of proteins for healing and tissue regeneration. Thromb. Haemost. 91:4-15. 
Argüelles D., Carmona J.U., Pastor J., Iborra A., Vinals L., Martinez P., Bach E. \& Prades M. 2006. Evaluation of single and double centrifugation tube methods for concentrating equine platelets. Res. Vet. Sci. 81:237-245.

Bames G.L., Kostelnuik P.J., Gerstenfeld L.C. \& Einhorn T.A. 1999. Growth factor regulation of fracture repair. J. Bone Miner. Res. 14:1805-1815.

Bailey A.J., Bazin S., Sims T.J., Le Lous M., Nicholetis C. \& Delaunay A. 1975. Characterization of the collagen of human hypertrophic and normal scars. Biochim. Biophys. Acta. 405:412-421.

Boswell S.G., Cole B.J., Sundman E.A., Karas V. \& Fortier L.A. 2012. Platelet-rich plasma: a milieu of bioactive factors. Arthroscopy 28:429-439.

Boswell S.G., Schnabel L.V., Mohammed H.O., Sundman E.A., Minas T. \& Fortier L.A. 2014. Increasing platelet concentrations in leukocyte-reduced platelet-rich plasma decrease collagen gene synthesis in tendons. Am. J. Sports Med. 42:42-49.

Carter C.A., Jolly D.G., Worden C.E., Hendren D.G. \& Kane C.J.M. 2003. Platelet-rich plasma gel promotes differentiation and regeneration during equine wound healing. Exp. Mol. Pathol. 74:244-255.

Carvalho A.M., Badial P.R., Álvarez L.E.C., Yamada A.L.M., Borges A.S., Deffune E., Hussni C.A. \& Alves A.L.G. 2013. Equine tendonitis therapy using mesenchymal stem cells and platelet concentrates: a randomized controlled trial. Stem Cell Res. Ther. 4:1-13.

Czubryt M.P. 2012. Common threads in cardiac fibrosis, infarct scar formation, and wound healing. Fibrogenesis Tissue Repair 5:1-11.

De Rossi R., Coelho A.C.A.O., Mello G.S., Frazilio F.O., Leal R.B., Facco G.G. \& Brum K.B. 2009. Effects of platelet-rich plasma gel on skin healing in surgical wound in horse. Acta Cir. Bras. 24:276-281.

Deschene K., Céleste C., Boerboom D. \& Theoret C.L. 2011. Constitutive expression of hypoxia-inducible factor- $1 \alpha$ in keratinocytes during the repair of skin wounds in horses. Wound Repair Regen. 19:250-259.

Enoch S. \& Leaper D.J. 2007. Basic science of wound healing. Surg. 26:3137.

Ferreira J.C., Souza M.V., Vilória M.I.V., Fonseca E.F., Vianna M.W.S. \& Costa J.C.M. 2007. Efeitos da monofenilbutazona na cicatrização por segunda intenção em equinos. Ceres 54:263-270.

Graziani F., Ivanovski S., Cei S., Ducci F., Tonetti M. \& Gabriele M. 2006. The in vitro effect of diferente PRP concentrations on osteoblasts and fibroblasts. Clin. Oral Implants Res. 17:212-219.

Greenwood J.E. 2010. Function of the panniculus carnosus - a hypothesis. Vet. Rec. 167:760.

Jacobsen L.C., Sorensen O.E., Cowland J.B., Borregaard N. \& TheilgaardMönch K. 2008. The secretory leukocyte protease inhibitor (SLPI) and the secondary granule protein lactoferrin are synthesized in myelocytes, colocalize in subcellular fractions of neutrophils, and are coreleased by activated neutrophils. J. Leukoc. Biol. 83:1155-1164.

Lefebvre-Lavoie J., Lussier J.G. \& Theoret C.L. 2005. Profiling of differentially expressed genes in wound margin biopsies of horses using suppression subtractive hybridization. Physiol. Genomics 22:157-170.

Liu S.H., Yang R.S., al-Shaikh R. \& Lane J.M. 1995. Collagen in tendon, ligament, and bone heling. A current review. Clin. Orthop. Relat. Res. 318:265-278.

Maia L., Souza M.V., Ribeiro Júnior J.I., Oliveira A.C., Alves G.E.S., Anjos L.B., Silva Y.F.R.S., Zandim B.M. \& Moreira J.D.C.L. 2009. Platelet-rich plasma in the treatment of induced tendinopathy in horses: histologic evaluation. J. Equine Vet. Sci. 29:618-626.

Maciel F.B., DeRossi R., Módolo T.J.C., Pagliosa R.C., Leal C.R.J. \& Delben A.A.S.T. 2012. Scanning electron microscopy and microbiological evalu- ation of equine burn wound repair after platelet-rich plasma gel treatment. Burns 38:1058-1065.

Marsolais D. \& Frenett J. 2005. Inflammation and tendon healing. Med. Sci. 21:180-186.

Mignatti P., Rifkin D.B., Welgus H.G. \& Parks W.C. 1996. Proteinases and tissue remodeling, p.427-474. In: Clark R.A.F. (Ed.), The Molecular Biology of Wound Repair. $2^{\text {nd }}$ ed. Plenum Press, New York.

Mishra A. \& Pavelko T. 2006. Treatment of chronic elbow tendinosis with buffered platelet-rich plasma. Am. J. Sports Med. 34:1774-1778.

Monteiro S.O., Lepage O.M. \& Theoret C.L. 2009. Effects of platelet-rich plasma on the repair of wounds on the distal aspect of the forelimb in horses. Am. J. Vet. Res. 70:277-282.

Mutsaers S.E., Bishop J.E., McGrouther G. \& Laurent G.J. 1997. Mechanisms of tissue repair: from wound healing to fibrosis. Znt. J. Biochem. Cell Biol. 29:5-17.

Rees H.M. \& Ecker E.E. 1923. An improved method for counting blood platelets. J. Am. Med. Assoc. 80:621-622.

Ruszczak Z. 2003. Effect of collagen matrices on dermal wound healing. Adv. Drug Deliv. Rev. 28:1595-611.

Schwartz A.J., Wilson D.A., Keegan K.G., Ganjam V.L., Sun Y., Weber K.T. \& Zhang J. 2002. Factors regulating collagen synthesis and degradation during second-intention healing of wounds in the thoracic region and the distal aspect of the forelimb of horses. Am. J. Vet. Res. 63:1564-1570.

Schultz G.S., Davidson J.M., Kirsner R.S., Bornstein P. \& Herman H. 2011. Dynamic reciprocity in the wound microenvironment. Wound Repair Regen. 19:134-148.

Schultz G.S., Ladwig G. \& Wysocki A. 2005. Extracellular matrix: review of its roles in acute and chronic wounds. World Wide Wounds. Disponível em <http://www.worldwidewounds.com/2005/august/Schultz/Extrace-Matric-Acute-Chronic-Wounds.html> Acessado em 29 out. 2013.

Soo C., Sayah D.N., Zhang X., Beanes S.R., Nishimura I., Dang C., Freymiller E. \& Ting K. 2002. The identification of novel wound-healing genes through differential display. Plast. Reconstr. Surg. 110:787-797.

Theoret C.L. 2008. Wound healing, p.5-27. In: Stashak T.D. \& Theoret C.L. (Eds), Equine Wound Management. $2^{\text {nd }}$ ed. Blackwell Publishing, Iowa.

Theoret C.L., Olutoye O.O., Parnell L.K.S. \& Hicks J. 2013. Equine exuberant granulation tissue and human keloids: a comparative histopathologic study. Vet. Surg. 42:783-789.

Thrall M.A. 2007. Diagnóstico dos distúrbios hemorrágicos, p.170-187. In: Ibid. (Ed.), Hematologia e Bioquímica Clínica Veterinária. Roca, São Paulo.

Vendruscolo C.P., Carvalho A.M., Moraes L.F., Maia L., Queiroz D.L, Watanabe M.J., Yamada A.L.M. \& Aves A.L. 2012. Avaliação da eficácia de diferentes protocolos de preparo do plasma rico em plaquetas para uso em medicina equina. Pesq. Vet. Bras. 32:106-110.

Wasterlain A.S., Braun H.J. \& Dragoo J.L. 2012. Contents and formulations of platelet-rich plasma. Oper. Tech. Orthop. 22:33-42.

Yamauchi M. \& Mechanic G.L. 1988. Cross-linking of collagen, p.35-92. In: Nimni M.E. (Ed.), Collagen. Vol.1. CRC Press, Florida.

Yang L., Witten T.M. \& Pidaparti R.M.A. A biomechanical model of wound contraction and scar formation. J. Theor. Biol. 332:228-248.

Young A. \& McNaught C-E. 2011. The physiology of wound healing. Surgery 29:475-479.

Zandim B.M., Souza M.V., Frassy L.M., Vilória M.I.V., Maia L., Fonseca C.C., Valente F.V., Moreira J.C.L. \& Magalhães P.C. 2013. Immunohistochemistry of factor VIII, histology and morphometry in equine tendon treated with platelet-rich plasma. Revta Bras. Med. Vet. 35:169-184. 